\title{
CORRIGENDUM
}

DOI: $10.3892 / \mathrm{etm} .2020 .9127$

\section{Dynamics of digital ulcers in systemic sclerosis}

CARMEN BOBEICĂ, ALIN LAURENȚIU TATU, MIHAELA CRĂESCU and LAURA GHEUCA-SOLOVĂSTRU

Exp Ther Med 20: 61-67, 2020; DOI: 10.3892/etm.2020.8572

After the publication of the above paper, the authors have realized that the last author's name was spelt incorrectly as "Laura Solovăstru". The correct spelling ("Laura Gheuca-Solovăstru") is presented above.

The authors regret that this error was not noticed prior to the publication of their paper, and apologize for any inconvenience caused to the readership of the Journal.

(c) (i) This work is licensed under a Creative Commons Attribution 4.0 International (CC BY 4.0) License. 